Peer-Reviewed Article

ISSN: 2162-3104 Print/ ISSN: 2166-3750 Online Volume 7, Issue 4 (2017), pp. 1065-1079

(C) Journal of International Students http://jistudents.org/ doi: $10.5281 /$ zenodo. 1035967

\title{
Strategies and Initiatives in Acculturation: Voices from Ghana
}

\author{
Susan Boafo-Arthur \\ Assumption College, USA \\ Dzifa A. Attah \\ Stellenbosch University, South Africa \\ Ama Boafo-Arthur \\ University of Ghana, Ghana \\ Thomas D. Akoensi \\ University of Kent, $U K$
}

\begin{abstract}
Culture shock and acculturation are salient aspects of any international study trip. Over the years, many institutions have devised several strategies to help international students transition to life in the host country. However, most of these strategies are insensitive to diverse cultural or country specifics. Drawing from Social Learning Theory, this paper provides narratives from four former students from the West African country of Ghana and how they navigated the process of acculturation in their respective host nations. The narratives discuss their feelings during the study abroad trip, some of the challenges they faced, and personal as well as institutional strategies that aided in ameliorating the experience of culture shock. A few recommendations for Student Affairs Practitioners are also provided.
\end{abstract}

Keywords: Black-African international students, Ghana, institutional strategies, personal strategies, social learning theory 
Technology and globalization have made education highly accessible to many students the world over. Scores of students from sub-Saharan Africa migrate to more advanced or developed nations around the world in pursuit of higher education. For instance, in 2013/14 and 2014/15, students from Nigeria were the fourth largest group of international students studying in the United Kingdom (U.K.) (Project Atlas, 2016), and in 2014/15 and $2015 / 16$ students from Nigeria were the $14^{\text {th }}$ largest group of international students studying in the United States (Institute of International Education [IIE], 2016).

Although there is not much research originating from Africa that focuses on decision-making practices with regards to international education (Maringe \& Carter, 2007), anecdotal evidence suggests that individuals from these countries are groomed to believe that an education from the West (or a more advanced society) is more desirable, and this may be a remnant from Africa's history of colonization. Irungu (2013) captured this dynamic when he says that (to Africans), having an education overseas is considered an achievement by almost everyone in the individual's society. Maringe and Carter (2007) also stated that African students "tend to migrate to their former colonial masters perhaps largely because of the derived cultural capital and language facility" (p. 466). The authors also found from one of their studies on why Africans chose to study in the United Kingdom that African students believed an education from the U.K. was superior and internationally recognized.

Often, however, the push for international education is without consideration for how to manage the consequent encounters that may prevent international students from making the most of their experiences. Many institutions offer the customary international student orientation, which often does not go beyond giving the already overwhelmed students more information to further inundate them. Moreover, the information given is not specifically tailored towards the different cultures the students come from and how they may deal with potential negative experiences they encounter. Caldwell and Hyams-Ssesaki (2016) summarized this conundrum by stating that higher education institutions (HEIs) are often more attuned to the diversity needs of domestic students, whereas the diversity needs within international students is often ignored.

The experiences of Black African international students are often distinct and different from that of international students of other races, including White African international students (Boafo-Arthur, 2014; Lee \& 
Opio, 2011). Research indicates that "Black-African students face discrimination from multiple sources (e.g., cultural differences, accents, and negative stereotypes about their countries of origin... and also have to deal with prejudice and discrimination based on their race, and faulty assumptions about their cultural heritage" (Boafo-Arthur, 2014, pp. 116118).

Rarely are their unique issues and challenges highlighted. Additionally, there is limited information on how Student Affairs Professionals (SAP) can manage and assist this unique group of students to transition effectively to life in their respective host cultures. Moreover, to report on best practices for Black African international students might also not be representative of the experiences of all Black African students and what might be most helpful in terms of their acculturation.

The purpose of this paper is to provide personal narratives on the experience of being an international student, as well as survival initiatives and strategies from the perspectives of former international students who studied in Norway, South Africa, and England. Specifically, the narratives will emphasize both personal and institutional strategies that helped curb the negative aspects of culture shock and that aided transition to a new academic environment. Lastly, recommendations for SAP are provided as a means of giving these professionals some ideas on how to work with this population.

\section{Acculturation and Social Learning Theory}

Drawing from psychological principles governing behavior and social interactions, social learning theory (SLT) posits that learning is contingent on the interaction between "the environment, personal factors (beliefs, preferences, expectations, self-perceptions, and interpretations), and the individual behavior" (Corey, 2013, p. 237). Per Bandura's (1971) explanation, "learning in a social environment can occur either through direct experiencing of the event, or from observing the behavior of others" (p. 3).

The dynamics of SLT can be applied to the acculturation experiences of international students in the sense that when international students through observation, readings, and other processes see other international students overcoming their challenges and transitioning successfully, they will be more likely to utilize similar strategies to overcome their challenges. The recommendation by Mesidor and Fly 
(2016), for instance, that institutions of higher education match incoming international students with other international students (mentors) already at the host institution as an aid to the adjustment process is predicated on the principles of SLT. Thus, international students may be better off when they have other international students as models or mentors from whom they can learn how to overcome their struggles than when they are just given generic information on how to cope.

For most international students, cultural adjustment issues; a sense of isolation and alienation; and difficulties with transportation, food, language barriers, the educational environment, and accommodation are recurrent issues at the forefront of acculturation needs $(\mathrm{Wu}$, Garza, \& Guzman, 2015). Of course, there is no perfection where humans and our experiences are concerned. Nonetheless, research from the field of psychology has consistently shown that humans have an overpowering need to belong and for social interaction, with a lack of healthy attachments resulting in dire consequences (see Baumeister \& Leary, 1995; Gailliot \& Baumeister, 2007; Knowles, Lucas, Molden, Gardner, \& Dean, 2010). We fail to thrive in environments that make us feel rejected and alone. Understandably, when an international student's basic need to belong is met, the transition process becomes relatively easier.

\section{NARRATIVES}

These narratives are from the personal experiences and accounts of four Ghanaians who studied for various postgraduate degrees at Stellenbosch University (South Africa); Norwegian University of Science and Technology (Norway); and University of Cambridge (U.K.). Their length of residence in the respective host nations ranged from 4 years for a doctorate degree in South Africa, to 2 years for those who studied in Europe (Norway and U.K. respectively). In all, there was one male (extrovert at University of Cambridge), and three females (South Africa, Norway, and the introvert at University of Cambridge). The labels 'introvert' and 'extrovert' were primarily used to distinguish between the narratives from the University of Cambridge as well as to demonstrate how personality differences influence the adjustment process. We did not find it necessary to apply the same descriptors/labels to the narratives from South Africa and Norway. 


\section{An Immersion: Experiences from South Africa}

I was extremely excited when I obtained admission to one of the top three universities in South Africa to pursue a three-year doctoral program in psychology. For me relocating to South Africa meant a new dawn and a lifechanging opportunity to achieve personal growth and career development from a global perspective. But alas, I was not adequately prepared for what lay ahead. Acculturating and assimilating to the South African culture was a bewildering and stressful experience. My first day in South Africa was exciting, although somewhat strange, as I grappled with adjusting to the time difference between South Africa and Ghana, new living arrangements, language barriers, harsh weather conditions, and dietary issues. In the days and months that followed, personal security, navigating my way to and from campus, local customs, racial discrimination, xenophobia, poor health, financial difficulties, complex academic conditions, and institutional demands become other prominent problems. Adjusting to these circumstances was a nonlinear and discontinuous process in the sense that environmental stress was not always predictable and different responses were required for different problems. In spite of this complexity and ambiguity, I managed to survive tough academic conditions and harsh living circumstances. In this regard, self-initiated, social and religious groups, and institutional-led initiatives were helpful.

The cultural novelty between South Africa and Ghana was great, but I was personally determined to accept, learn, and adapt to new behaviors in this cultural setting. Therefore, I periodically challenged myself to try new ways of doing things in order to help myself successfully incorporate learning from the host culture. For instance, I tried new food, engaged in social activities commonly practiced by South Africans (e.g., wine tasting, hikes, and braais), took part in programs organized by the international office (e.g., fashion shows, sporting activities, and cooking competitions), and registered for courses, workshops, or seminars that offered academic and professional support.

Additionally, in the process of adaptation I received continuous support from a range of social contacts in and outside South Africa, including friends and family back in Ghana and beyond, a relative living within South Africa, co-nationals (i.e., students and nonstudents), and international sojourners from other countries. Some of the contacts based in South Africa were also new to the setting; others had months or years of living in this setting. Maintaining and establishing one-on-one and group 
social contact with such groups of people enhanced the transitional process. In the case of the former, it was reassuring to know that intercultural stress was not a unique circumstance and that other students go through similar challenges and struggles. In the case of the latter, it was helpful to learn lessons and best practices from others who had adjusted to the host culture successfully. The church community and the association of Ghanaians in Stellenbosch aided and mobilized such social interaction through various events.

At the institutional level, the international and postgraduate office also hosted a range of innovative activities and programs to facilitate new learning and adaptation. For example, I participated in brief lunch meetings, competitions, seminars, and workshops organized by the international office. Here, I interacted and exchanged cultural experiences with other students.

To a large extent, my successful adaptation to the host culture was rooted and strengthened by a good supervisor-student relationship. My supervisor understood the importance of this relationship and the sort of impact it had on my intellectual output. Therefore, he consistently sought to maintain a healthy and positive relationship. The kind of support my supervisor offered extended beyond meeting my academic needs. In addition, he ensured I was socially, physically, financially, and emotionally stable; in circumstances where he was unable to help directly, he made appropriate referrals. Adapting to life on campus and in South Africa in general would have been a difficult process without his consistent assistance and support. Relocating from the known to the unknown can be a bewildering experience, but with the right kind of support and resources, it is just another life challenge that demands change, development, and maturation.

\section{The International Student Village: Experiences from Norway}

During my graduate education in Norway, I realized that my program was structured in such a way that students had two cohorts, so to speak: there was a group of co-nationals who began their various programs in the same academic semester as myself and the larger group of international students on the university campus. Outside of the general orientation sessions, international students also attended orientations and other international meetings at various times during the year and lived in the 
same locale/neighborhood. These activities were coordinated by the university's international students' office.

The living arrangements consisted of four students living in a fourbedroom flat and sharing common areas. A distinct advantage of this system was that students got to meet other local and international students, visiting scholars, study-abroad students from various parts of the world, Erasmus Mundus scholars, and many other categories of international students. In effect, the student village was a global village. In my two years in Norway, I had roommates from Norway, China, South Korea, Spain, Latvia, Sweden, Germany, and the Czech Republic. In addition, older students from various countries were already at the host institution. These older international students often served as mentors and aided in transition efforts by dispensing valuable information on issues as diverse as accommodation, shopping, transportation, opening bank accounts, food, and education. As a new student unfamiliar to the country, culture, and educational system, I found it beneficial to live with other international students and to share cross-cultural information. Another benefit was being mentored by other students from my country of origin. In a sense, there was never truly a sense of alienation or isolation.

In addition to this, transportation was quite simple - all a student needed was a bus pass and you could go practically anywhere you wanted in the city. Sidewalks and pedestrian walkways were common, and so you never felt impeded, regardless of your mode of transportation. Typically, new international students do not know the area and have to reside in the locale for an extended period to navigate around the city by themselves. It makes sense then to provide international students with accessible transportation. Ultimately, this also aids in the transition process, as students feel more confident and more comfortable in their new surroundings.

Finally, food is important to all humans, and finding and eating food that is familiar can reduce anxiety about life in a new country. For most cultures, great conversations are also had around food. Parties and other social occasions often feature food from one's culture. The paucity of food from one's culture will obviously limit the number and types of social activities that students engage in. As a fringe benefit, there were also several specialty grocery stores such as African food stores, Asian food stores, Arab food stores, and the like, catering to the culinary needs of the aforementioned populations. These collectively made me feel at ease within the environment. 
I find that the three issues highlighted earlier are a core aspect of an international student's life. Finding commonalities in our experiences often strengthens bonds, reduces culture shock, mitigates the experiences of alienation, and overall makes for a more positive student. The statistics on international student retention for the United States are not clear; however, institutions are more likely to increase international student retention if students are given opportunities to connect with other students and thereby satisfy that need to belong as described by Abraham Maslow's hierarchy of needs. As such, even if they feel disconnected from host students, international students still have individuals from their countries or other countries to engage with. Overall, there are many struggles in the life of an international student; however, when a student's needs in any one or several areas are met, the potential for negative consequences in other areas is truncated.

\section{From the Eyes of an Extrovert: Experiences from the United Kingdom}

As an African student without any European travel experience, my admission to an M.Phil. degree, which later culminated in a Ph.D. program in a U.K. university, was full of anxieties. These anxieties centered around academic achievement; coping with the weather; building relationships with colleagues, academics, and institutions of interest; and participating in activities relevant to my personal and academic development, among others. During the course of my studies, several institutional and personal initiatives coalesced into stronger and better adaption to this new environment. I outline some of these initiatives.

First, I must establish that academic institutions that are internationally focused must embrace learning from various cultures while responding to cultural diversity infused with cross-cultural internationalization. These are my conclusions after several years studying at this institution. An association of Ghanaian students present at my university assisted with this assimilation and adaptive process to a European life beyond the shores of Africa. Various fora held by the association on students' expectations provided the needed atmosphere to air my anxieties and receive appropriate guidance from alumni on the course I was studying and to learn from the experiences of others from various programs. One of the most profound statements by an alumna from an unrelated discipline to mine was quite profound: "No Ghanaian student has ever failed here at 
Cambridge." This bolstered my confidence, and I felt reassured that I was capable of breaking new ground, which I eventually did.

The opportunity to allow members of a given group to forge close links and to bond can have a negative effect, however. The security of these associations may create an atmosphere that affords so much comfort and collegiality that individuals might not want the challenge of engaging in interactions beyond this circle. This is disadvantageous to personal growth, as I observed such clinging prohibited others from making friends or associating beyond their group. Nonetheless, another takeaway from this forum was learning about shops or streets where we can have access to meals, spices, and ingredients that were culturally specific. I could purchase spices and make food that was close to the cuisine at home. This often attracted my housemates to the kitchen and gave us an opportunity to chat about various issues - fraternization in the "Jesus Kitchen," as we called it, became a core routine, and my housemates enjoyed my meals. On crossinstitutional internalization, the Ghana Association's links with the African Union at Oxford University enabled another bigger platform on which to share and debate issues of mutual importance, including, but not limited to, academic life, as well as developments on the African continent. I felt a sense of achievement to have participated in the first Pan-African conference in the $21^{\text {st }}$ Century at Oxford University.

Again, at the institutional level, my department was collegial to the extent that I could approach any of my lecturers at any point in time to have a discussion of on-going issues in a healthy atmosphere. Having professionals or lecturers from the Black-minority ethnic (BME) groups was also crucial, as it provided me with a sense of belonging and a role model to aspire to- one of them continues to serve as a mentor on several of my academic developmental fronts. This was key to my assimilation in this new, very demanding academic environment. I recall one fateful afternoon when I attended a one-hour full lecture and struggled with comprehending the lecture, due mainly to the accent of the professor. Out of frustration I left the class and approached a different lecturer from my ethnicity; he calmed me down, empathized with my situation, and gave me tips on how to overcome the situation. I left his office relieved and in very high spirits-a recall of this encounter generates raucous laughter whenever we meet. These open-door policies practiced by my department afforded me the opportunity to seek assistance whenever it was practicable. I have used such opportunities offered by other professors of the host nation. 
On the personal initiative front, to assimilate and escape boredom, I explored the nightlife of the city and found a club that was noted for embracing cultural diversity by playing music and hosting parties and themes I could associate with. My outgoing personality facilitated this move. This was one of the best things that happened to me. Friday nights were spent at this club, fraternizing with people of diverse cultures and countries and, as I used to say, "dance the tree out of my soul"-an aphorism derived from the name of the night club: "Soul Tree."

\section{From the Eyes of an Introvert: Experiences from the United Kingdom}

In my final year as an undergraduate, two things were important to me: finishing with a first class (referred to as summa cum laude in the United States) and embarking on a master's degree before settling down to work. I was pleasantly surprised when I received an offer letter detailing a fully sponsored M.Phil program in one of the best schools in the world. I was beside myself with joy and deferred my M.Phil in Ghana to take on the Development Studies program in the United Kingdom.

Going to the United Kingdom, I had great expectations and a lot of anticipatory excitement because I had heard a lot about how gorgeous life outside Africa is. I quickly found out that I was naively unprepared. Upon arrival, I struggled with the weather, food, and navigating around the campus, as well as academic work, which was my reason for going. I was homesick throughout my stay in the United Kingdom and eventually had to return home earlier than my scheduled departure date. I took a lot of things for granted and was not adequately prepared for what I experienced. At one point, I wished I could abandon the course and go home, but fear of cultural and societal rejection kept me going. I know that my experience could have been enjoyable if other avenues had been created to assist introverts and international students leaving home for the first time.

These negative experiences notwithstanding, my personal strategy for coping with the boredom, loneliness, and homesickness was to rely on computer games. Because of my introverted personality, I could stay indoors for weeks and play games the entire time. One of the most useful resources I had that helped ease my loneliness was the Cambridge University Ghanaian Society. In this society, I met other Ghanaians, some of whom were very supportive. This support really helped me to adjust and complete my master's program. Through the association, I met an old friend who helped me find my way around town, especially to grocery stores and 
to find relevant accessories that I needed at better rates. An older Ghanaian lady was most helpful as she continually encouraged me to experiment with English cuisine and to be more adventurous with my palate. With the encouragement and experiences shared by other students, I forged on.

I also encountered awesome learning experiences that I can never forget. The library was a great delight, as every book relevant to my education was readily accessible. I also participated in some conferences that prior to my master's program I had never considered. These were insightful as well as intellectually and academically stimulating. Faculty members also tried their very best to help us settle in, but as was earlier expressed, individual characteristics must be considered, especially where international students are concerned.

By the end of the program I had made friends with other international students who had previously been exposed to life outside their countries quite often, and they suggested trips during the holidays to other countries. During the summer, we went on short trips to Italy, Spain, Belgium, and France. These trips were highly enjoyable and they helped ease the stress of the school environment, as well as make me forget about my desire to go home. Adapting successfully to the U.K. and Cambridge environment was greatly enhanced by the people I met. Despite the bittersweet experiences, it was a worthwhile opportunity, and I have never regretted it. I know that next time I will be in a better position mentally, socially, and psychologically to fully engage in the experiences that such opportunities present.

\section{RECOMMENDATIONS}

Being an international student in any environment can be an exciting, yet scary process. From SLT, we know that we learn by observing how others have navigated similar circumstances. The narratives included here describe personality differences; discomfort; unfamiliarity; and struggles with culture, food, and transportation and how these collectively destabilized the process of acculturation. From an optimistic perspective, the narratives also describe how social connections with others, either in the community or with older international students, supportive relationships with advisors, and engagement with other international students helped the adjustment process. What this may imply is that fostering nonthreatening and assimilative social connections may ease the transition process. For institutions and SAPs, this might mean minimizing the typical approach to combating culture shock. 
Incorporating practical events that consider Ghanaian, or even more broadly, African social ethics of collective responsibility, interdependence, and reciprocal obligations (Gyekye, 2013) might also be necessary. Central to this is the notion that the Ghanaian cultural context is somewhat based on a mentorship model. That is, there is the expectation that individuals who are more advanced in a skill or area are supposed to mentor or guide others who are yet to be skilled. There is also the concept of "nnoboa" which in rural farming communities was a means by which a farmer sought assistance from other farmers within the community to help in cultivation (Gyekye, 2013, p. 230). This was done in a spirit of mutual reciprocity as refusing to help others implied that if you needed help, the probability of others helping you was lessened.

Even within the Ghanaian secondary education system, students in their final year typically mentor freshmen or incoming students. Mentoring relationships are also reflected in trade and vocational schools where apprentices are coached and guided by the older trainees with more experience. The Ghanaian proverbs:

- "Onipa nua ne onipa (A human being's brother is a (or, another) human being)";

- "Onipa yieye firi onipa (The well-being of man depands on his fellow man)"; and

- "Wo nsa nifa hohorow benkum, na benkum nso hohorow nifa" the right arm washes the left arm and the left arm washes the right arm)" (Gyekye, 2013, pp. 225-231)

amplify the significance of mutual responsibility and reciprocity that are central to Ghanaian and African cultural values discussed previously. Gyekye further explains that it is in acts of hospitality, generosity, concern for others, and a willingness to help others to achieve their goals, that this ideal of brotherhood is depicted.

Gyekye (2013) highlights mutual helpfulness as consistent with African moral thought and cultural practice. As such new international students from Ghana, often look to other students who have been in the host nation for a longer period to, as it were, "show them the ropes" as is typically done in their countries of origin. Conversely, students who have been in the host nation for a longer period also seek mentorship opportunities with newer students. For SAPs working with Ghanaians, or Africans in general, it may be helpful to determine how to translate these cultural values into practical experiences for their student populations. Mesidor and Fly (2016) discuss similar ideas with their suggestion that 
SAPs can connect with longer staying international students to serve as mentors for new international students who hail from similar cultural backgrounds. In turn, the latter can also act as mentors to new international students, after they have acclimatized to the host country. We must caution here that the purpose of advocating for mentors to have mentees from similar cultural backgrounds and not necessarily Ghanaians is because we are cognizant of the fact that in some institutions, the population of Ghanaians or Africans may not be significant enough to develop an entire program to cater to their needs. However, if there are others of similar backgrounds, they can be matched appropriately and still benefit from the mentoring process.

As exemplified by the narratives within this text, all the writers admitted that their acculturative process was aided by other international students who knew or had a deeper understanding of how the host institutions or countries function, and by connecting and networking with others who had been residents longer than them, they were able to get situated with less hassle than they would have had they not known anyone. Also highlighted in the text, is the fact that all these mentorship models or processes were informal and within the sub-groupings of international students. So SAPs may need to find ways to formalize this process so that from the first day of arriving in the host country, or even prior to arrival, students are connected.

In conclusion, student affairs professionals may also need to learn, relearn, or adapt skills that can be necessary in working with students from different cultures considering the personality differences within their student populations. Lastly, international students must understand that despite the seemingly precarious position they find themselves in, they also have to be willing to make appropriate connections with others to hasten their skills in adapting to a new environment.

\section{REFERENCES}

Bandura, A. (1971). Social learning theory. New York, NY: General Learning Press.

Baumeister, R. F., \& Leary, M. R. (1995). The need to belong: Desire for interpersonal attachments as a fundamental human motivation. Psychological Bulletin, 117, 497-529. 
Boafo-Arthur, S. (2014). Acculturative experiences of Black African international students. International Journal for the Advancement of Counselling, 36(2), 115-124.

Caldwell, E. F., \& Hyams-Ssekasi, D. (2016). Leaving home: The challenges of Black-African international students prior to studying overseas. Journal of International Students, 6(2), 588-613.

Corey, G. (2013). Theory and practice of counseling and psychotherapy. Belmont, CA: Wadsworth.

Gailliot, M. T., \& Baumeister, R. F. (2007). Self-esteem, belongingness, and worldview validation: Does belongingness exert a unique influence upon self-esteem? Journal of Research in Personality, 41(2) 327-345.

Gyekye, K. (2013). Philosophy, culture, and vision: African perspectives. Accra, Ghana: Sub-Saharan Publishers.

Institute of International Education (2016). Fast facts 2016. Open Doors Report on International Educational Exchange. Retrieved from http://www.iie.org/Research-and-Publications/OpenDoors\#.WNqeqI5Jnm0

Irungu, J. (2013). African students in the US higher education system: A window of opportunities and challenges. In H. C. Alberts \& H. D. Hazen (Eds.), International students and scholars in the United States: Coming from abroad (pp. 163-180). New York, NY: Palgrave MacMillan.

Knowles, M. L., Lucas, G. M., Molden, D. C., Gardner, W. L., \& Dean, K. K. (2010). There's no substitute for belonging: Self-affirmation following social and nonsocial threats. Personality and Social Psychology Bulletin, $36(2), 173-186$.

Lee, J., \& Opio, T. (2011). Coming to America: Challenges and difficulties faced by African student athletes. Sport, Education and Society, 16(5),629-644.

Maringe, F. \& Carter, S. (2007). International students' motivations for studying in UK HE: Insights into the choice and decision-making of African students. International Journal of Educational Management, 21(6), 459-475.

Mesidor, J. K., \& Fly, K. F. (2016). Factors that contribute to the adjustment of international students. Journal of International Students, 6(1), 262-282.

Project Atlas (2016). International students in the United Kingdom. Institute of International Education Atlas of Student Mobility. Retrieved from http://www.iie.org/Services/Project-Atlas/United-Kingdom/InternationalStudents-In-UK\#.WNqhYo5Jnm2

Wu, H.-P., Garza, E., \& Guzman, N. (2015). International student's challenge and adjustment to college. Education Research International, 2015, 1-9. doi: $10.1155 / 2015 / 202753$. 
DR. SUSAN BOAFO-ARTHUR is an Assistant Professor in the Department of Human Services and Rehabilitation Studies at Assumption College in Worcester, Massachusetts. Her research interests are in the area of international students acculturation and transition issues with particular emphasis on the experiences of Black African nationals in the diaspora. Email: sboafoarthur@gmail.com

DR. DZIFA A. ATTAH is a clinical psychologist by profession and is currently engaged in research and private practice in Ghana. Dr. Attah has research interests in child sexuality, child and adolescent psychology, and related cultural issues. More recently, she has developed a keen interest in study abroad experiences, as a result of her own lived experiences of studying overseas and reintegration after international sojourn in South Africa. Email: dzifaattah@yahoo.com

DR. AMA BOAFO-ARTHUR is a lecturer in the Department of Distance Education at the University of Ghana. Her research interests revolve around child and youth studies, adolescent reproductive health, multiculturalism, and delinquency. Her interactions with students and peers, alongside her own international travel experiences as a student, has piqued her interest in study abroad experiences and the consequent impact on the sojourner. Email: amboart@yahoo.com

DR. THOMAS AKOENSI is a Lecturer at the University of Kent, UK. He is the Senior Tutor for the BA Social Science and BA Criminal Justice and Criminology programmes at the Medway campus where he provides pastoral care to both home and international students as well as providing specific advice and support to individual student problems. He also directs students to other avenues of student support whilst liaising with other departments within the University. Email: T.Akoensi@kent.ac.uk 